Acta Universitatis Wratislaviensis No 3836

Anglica Wratislaviensia LVI, Wrocław 2018

DOI: 10.19195/0301-7966.56.5

Elżbieta Litwin

ORCID: 0000-0002-0170-1875

University of Wroclaw

elzbieta.litwin@uwr.edu.pl

\title{
Method-ising Cognitive Truth: The Paradigm of Subtext in Baz Luhrmann's Silver-Screen Vision of Romeo and Juliet's Wedding
}

\begin{abstract}
A case study of the wedding scene in William Shakespeare's Romeo + Juliet directed by Baz Luhrmann (1996), this article is a hermeneutic exploration of the truth pursuits within the subtext from the empirical perspective of a practicing director and a semiotician, in accordance with the principles of the Method acting technique. The author proposes a new, space-negotiated definition of subtext as a separate cognitive unit, based on the multilayered interdependences within the directorial semiotic triad of word-emotional action-mise-en-scène. In a minute shot-by-shot analysis, the author examines the hermeneutic collocations in-between the elements of the triad, and demonstrates the ways cognitive spaces become subtextual statements within each shot, as well as how the internal subtexts shape the metasubtext of each shot in order to arrive at the megasubtext of the scene - and subsequently the total subtext of the entire story in a cultural text. Aspects of the evolution of the subtext representations are analyzed within the triad of word-emotional action-mise-en-scène, against the backdrop of the epistemological pursuits of the truth. How do we reach the truth in a cultural text? What components of the film language rule the expression of the truth in a cultural text?
\end{abstract}

Keywords: subtext, metasubtext, megasubtext, the Method, the triad of word-emotional actionmise-en-scène, cognitive truth, Romeo and Juliet

\section{Introduction}

The Japanese have a word to describe the quality of space and time between people: ma'ai. In the martial arts the ma'ai is vital because of the danger of mortal attack. On the stage, the space between actors should also be continually endowed with quality, attention, potential and even danger. The ma'ai must be cultivated, respected and sharpened. The lines between actors should never go slack. 
What is the truth in performance? How do we gain access to the truth in a narrative story on the screen? In her insightful book on the Method ${ }^{1}$ acting technique, Changing Direction, Lenore DeKoven states that "we watch movies for the subtext" (38), indicating that subtext is the truth-formation platform, and identifies subtext with the actor's action. However, if that is the case, how do we transition from pictorial thinking to subtextual thinking? Arguably, a visual story is a sequence of subtexts, and that is what the director directs and the actors act. If, as Ludwig Wittgenstein proves, "the sense of a sentence is the method of its verification" (1999), the epistemological canon of reading the subtext is immanent in the verification of the directorial syntax of the Method operating within the semiotic triad of word - emotional action - mise-en-scène.

Over the years of my experience of working with American Method actors as a practicing director I have developed a technique of subtextuality chains, which function as sequences of free, interrelated emotional associations operating within the directorial triad of word - emotional action - mise-en-scène. I have found it useful to think of these associations as separate cognitive spaces and independent semiotic units. The consistent efficiency of the phenomenon has reassured me that we have been walking a new path; arguably, we are witnessing a new paradigm being born in Method director-actor communication, and possibly far beyond: the paradigm of subtext.

The seeds for the spatial nature of subtextuality have been sewn by Umberto Eco's in his concept of codes:

a code organizes signs; $[\ldots]$ codes provide the rules which generate signs as concrete occurrences in communicative intercourse. Therefore the classical notion of 'sign' dissolves itself into a highly complex network of changing relationships. Semiotics suggests a sort of molecular landscape in which what we are accustomed to recognize as everyday forms turn out to be the result of transitory chemical aggregations and so-called 'things' are only the surface appearance assumed by an underlying network of more elementary units. (49)

Similarly, Keir Elam sees "code [...] as the ensemble of rules — known to both transmitter and destination - which assigns a certain content (or meaning) to a certain signal." (35). However, both Eco and Elam put stress on signs, and treat codes as merely devices of structural organization that remain within the molecular domain of sign relationships.

${ }^{1}$ It is important to draw a clear line between the prevailing American acting technique, the Method, and Constantin Stanislavski's System. While Stanislavski mostly worked from his instinct and never managed to define the formula of his System, the Method is a well-structured and specific recipe for actors and directors. Although initially inspired by the teaching of Stanislavski as reflected in Lee Strasberg's approach at the Actors Studio, the Method has developed into an independent acting technique, and over the years - into several branches or schools of the Method, significantly distinct from, if not in opposition to, Stanislavski's System.

I will be referring to the Method as taught by Stella Adler and Sanford Meisner, and further structured by Lenore DeKoven. 
In my study I go a step further, and propose a spatial concept of subtext as a truth-formation element. By a parallel with the spatial concept of ma'ai referred to in the opening quote, introduced to the theater studies by Anne Bogart to describe the quality of the physical space (104), I have used the concept of ma'ai to enquire about the cognitive space.

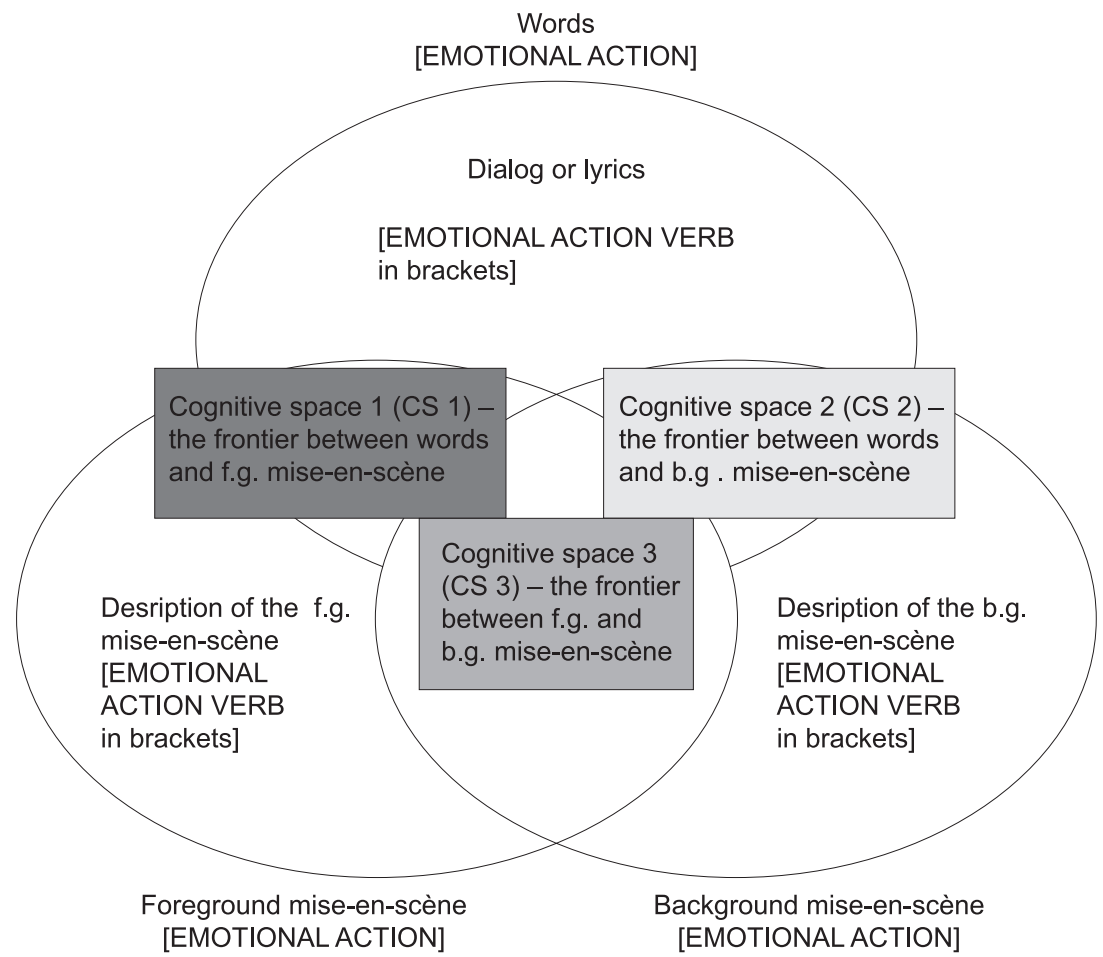

Figure 1: The visual representation of subtext as the cognitive space in-between the directorial triadic tools of word - mise-en-scène - emotional action, determined by the nature of their relationship

Therefore, I propose a definition of subtext as the cognitive space in-between the directorial triadic tools of word - mise-en-scène - emotional action, determined by the nature of their relationship. In other words, I approach subtext as the frontier or the intersection of the sets within the directorial triad, a separate semiotic unit, and an active agent - the domain in which the truth of the character is revealed. The purpose of this paper is the cross-examination of this cognitive space and therefore the truth-formation processes - on the canvas of the wedding scene in Baz Luhrmann's film adaptation of William Shakespeare's Romeo + Juliet (1996), and based on the directorial semiotic triad of word - emotional action — mise-en-scène, in accordance with the principles of the Method acting technique as illustrated in Figure 1. Blessed by my double empirical insight as a practicing director and a semiotician, I will take the liberty of an interpretative analysis evolving within a hermeneutic circle. 
By no means am I claiming that such was the intention or the artistic premise of the William Shakespeare's Romeo + Juliet director or the actors; my choice of this particular scene is based on its impressive word - emotional action - mise-en-scène balance and its abundant Method compatibility. ${ }^{2}$

\section{The shot-by-shot analysis of the subtext formation process}

The wedding scene is the greatest turning point of William Shakespeare's Romeo + Juliet [TC 53:45 - 55:10], and — in its faithfulness to the play — it elevates the sanctity of marriage. ${ }^{3}$ Luhrmann enhances the sacred imagery within the Shakespearean language by a consistent mise-en-scène campaign of sacred leitmotif artifacts: the monumental statue of Christ, the ubiquitous presence of the cross and the Marian art - as well as the aquatic motifs apparently and consequently referring to sacramental rituals $^{4}$ (Litwin 2017) and leading us directly to the central sacrament of Romeo and Juliet: the marriage. It is the pivotal scene around which everything else evolves, and which makes Romeo and Juliet a husband-and-wife story, and not merely a lovers-story.

The mise-en-scène of the scene directly preceding, in which Nurse brings the anxious Juliet the good news from Romeo, prepares us for the statement of the sanctity of marriage in everyday life. The subtext created by the clash of the ordinary - the casually cluttered space, Juliet's plain clothes and her unpretentious manner - with the extraordinary represented by the Marian shrine illuminated by the intensely red light, indicates that something extraordinary is about to happen to ordinary people.

As illustrated in Figure 2, the last shot of the scene intensifies the anticipation. While in the foreground Nurse rejoices as she announces the word from the "husband to make you a wife", her red suit breaks the harmony and brings in the connotation of alert, danger, suffering - or perhaps the association of a violent bloodshed. That mise-en-scène in the juxtaposition with the words of joy creates the subtext of joyful anticipation (CS 1). In the background, the mise-en-scène introduces the motif of the Last Supper in a painting on the wall - suggesting a

2 The assumption that the William Shakespeare's Romeo + Juliet actors are working in accordance to the Method is based on the fact that it has become the leading approach to acting in the U.S., and has "influenced, directly or indirectly, almost every American actor" (Weston 1996: 153).

3 Abundant references to sanctity in Romeo and Juliet can be found in A.D. Nuttall, Shakespeare the Thinker (110-111).

${ }^{4}$ I discussed extensively the sacred motifs of William Shakespeare's Romeo + Juliet in my presentation, "Trust, Infinity and the Philosophy of the Divine Mercy. Breaking the Star Crossed Paradigm in William Shakespeare's Romeo + Juliet by Baz Luhrmann", at the 2017 Congress of the European Shakespeare Research Association in Gdańsk. 
parallel with the sacrament of the Eucharist, and therefore with Christ's communion with His Church, the Church being Christ's bride (Holy Bible 2 Cor 11:2), and such is the subtext (CS 2). At the same time, the Eucharist is the anticipation of Christ's Passion, and the Church's participation in it (Catechism of the Catholic Church 1366). If so, what could be a better canvas for the subtext of marriage as a vocation, a call of love, a mission - and a joyful one since the Nurse's emotional action is to rejoice (CS 3)? If the mission of marriage is to carry the cross of love with Christ, it must end in the joyful fulfillment of resurrection - which consequently becomes the metasubtext of the shot. The statement is sealed by the lyrics bridging the scenes: "Everybody's free..." which introduce us to the major theme of the verbal layer in the next scene, namely that God gives us freedom. Arguably, throughout the wedding scene, the verbal layer (the lyrics and Father Lawrence's speech) connotes God's presence.

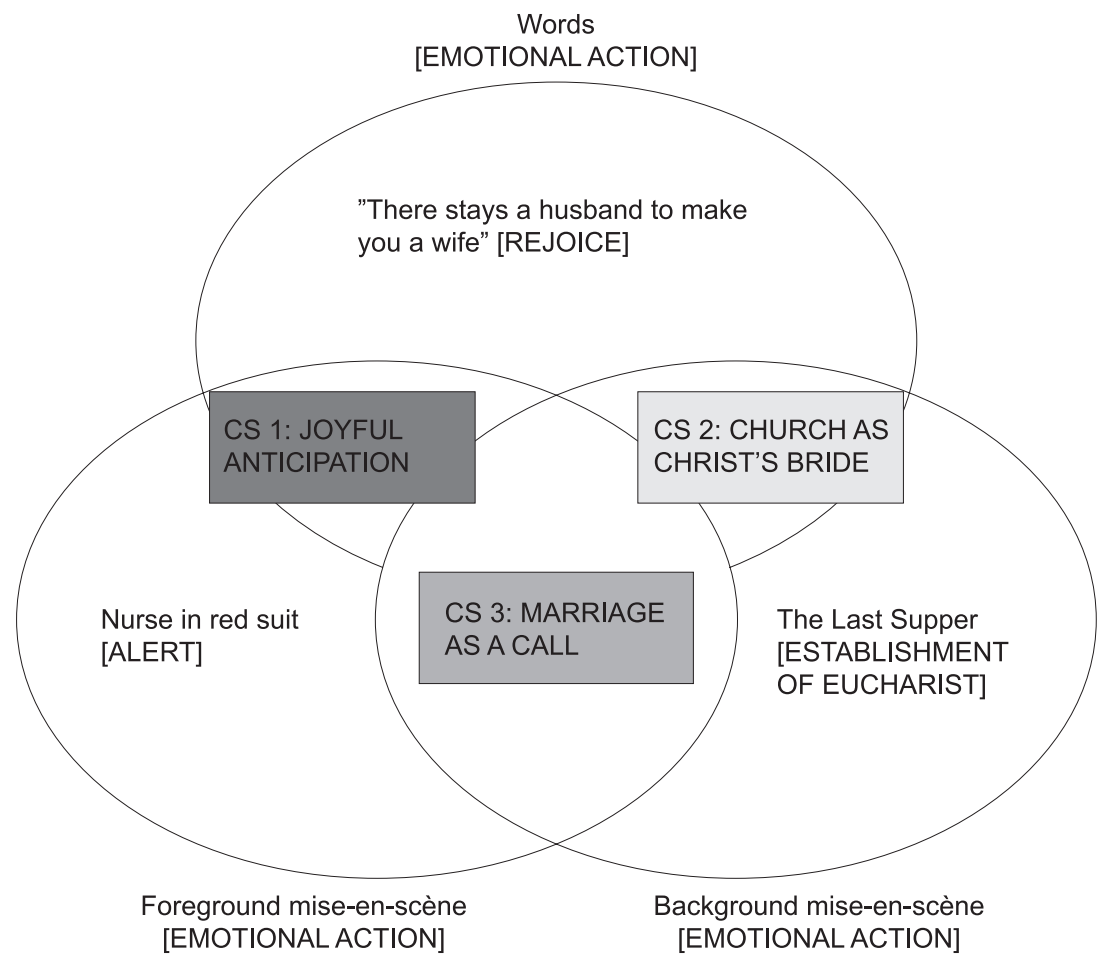

Figure 2: The breakdown of the subtextual interdependences in the final shot of the scene directly preceding the wedding scene [TC 53:40] 


\section{SHOT A (Figure 3)}

Mise-en-scène-wise, the scene of the wedding ceremony in the church begins with a boom-down shot showing off the altar art in a majestic descent, coming to a close and revealing the choir boys in the foreground as they sing. In many ways this shot is unique as the frame operates in a multi-layered perspective resulting in multi-layered subtextuality - and the mise-en-scène dominates the subtextual connotations, therefore the diagram is more elaborate. The choir boys are the background for the soloist and in their background we see Juliet walking down the aisle towards Romeo awaiting her at the altar - and Father Lawrence in the further background. The background-within-the background rhapsody is backed by the monumental art of the altar. In the very foreground, we see the choirmaster's hand, as if God's conducting the scene and the heroes' lives - as well as the heart-warming soloist's song: "Brother and sister, together we'll make it through..." (thus the subtext of brotherhood in CS 1), which could be sung by Christ himself. He seals Juliet's innocence, and justifies Romeo's manliness as a cardinal virtue by His Divine orchestration (CS 2). The overall subtext of the foreground space culminates as harmony in togetherness (CS 3).

In the central background Juliet, in a white dress - like a white sailing boat approaching a safe harbor - is walking down the aisle. There is loneliness and determination in her steady step as she is heading towards her destiny. The direction of her movement, away from us, suggests independence; and at the same time the direction away from the choir boys and their innocence connotes growing up and assuming her own life direction (CS 4). Or perhaps she is bestowing her innocence upon the world by bringing it to the altar. She is walking towards the altar, "the center of the world", 5 where Romeo, her safe harbor, is awaiting her and the space in-between them connotes union (CS 5). In the further background, Father Lawrence keeps his position at the altar, which marks their destiny (CS 6). The altar paintings in the furthermost background frame the shot bringing it to a close in a Divine statement: Romeo and Juliet's union is their Divine destiny (SC 7). It comes out of their growing up and assuming their own independent life direction - in brotherhood, and by the Divine orchestration. The furthermost background completes the hermeneutic circle of the shot by engaging in a relationship with the foreground: the altar art juxtaposed with the choir boys orchestrated by the Divine hand connotes prayerful support (CS 8). The central subtextual message (CS 9) becomes the communion of God and saints.

5 Prof. Jerzy Limon analyzes the Cross-based symbolism of the altar within the architectural design of the church in Między niebem a scena (329). I referred to it more extensively in my presentation, "Trust, Infinity and the Philosophy of the Divine Mercy. Breaking the Star Crossed Paradigm in William Shakespeare's Romeo + Juliet by Baz Luhrmann", at the 2017 Congress of the European Shakespeare Research Association in Gdańsk. 
If we examine the words/lyrics delivered by the heavenly innocent voice of the soloist ("Everybody's free, everybody's free to feel good - to feel good. Brother and sister, together we'll make it through...") within their relationship to each and every one of the mise-en-scène layers, we receive the subtextual connotation of God's freedom and God's greatness as a token of Romeo and Juliet's fulfillment in love (CS 10). Therefore the overall subtext of the shot, the metasubtext being the median of the subtextual CS 1-10, is the communion of God and saints in Divine freedom and in prayerful, heavenly support for Romeo's virtue of manliness and Juliet's "yes" to the cross of the marriage in their journey together. Whether or not they will take full advantage of it poses a separate question...

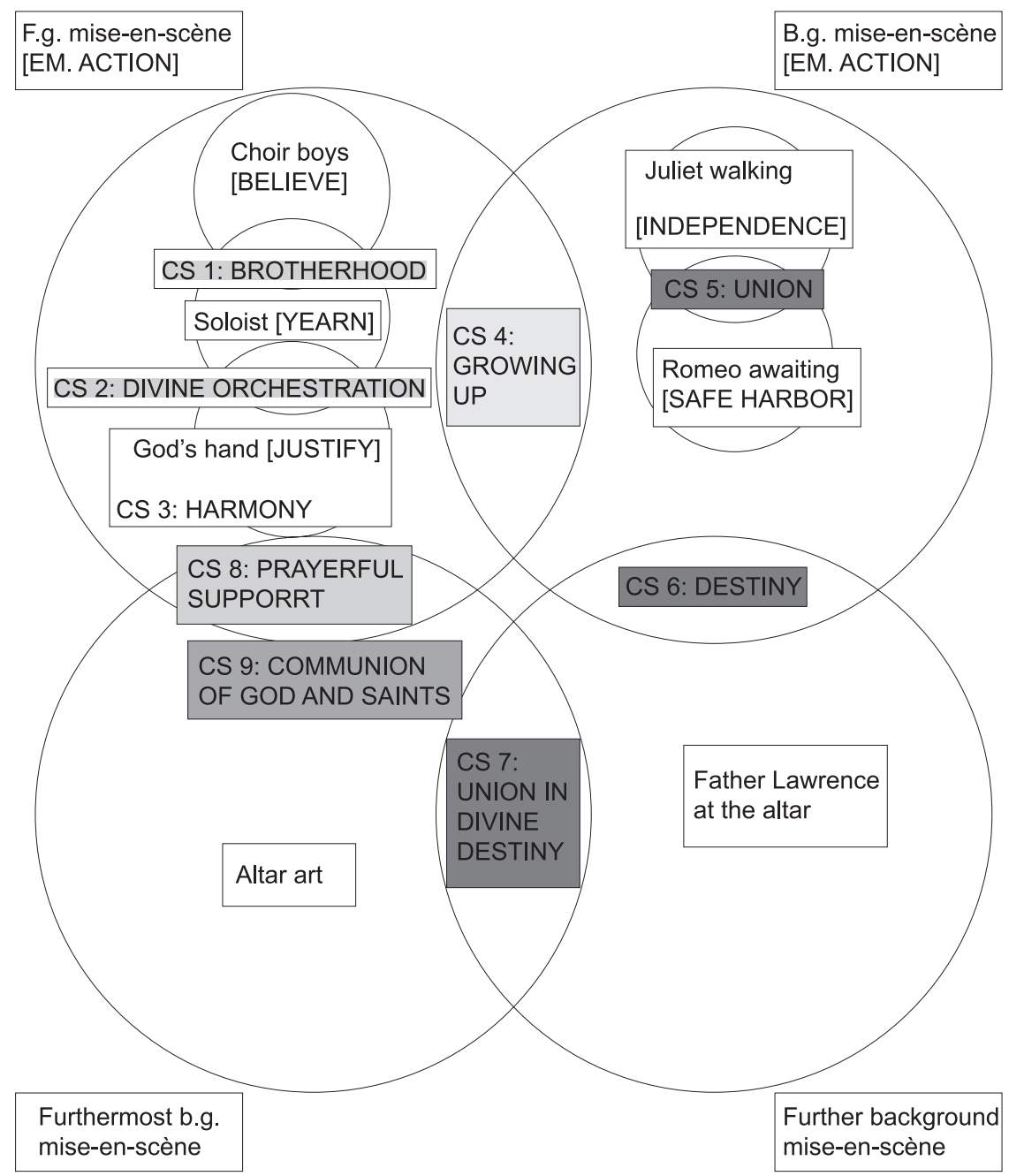

Figure 3: The breakdown of the subtextual interdependences in shot A [TC 53:45-53:59] 


\section{SHOT B (Figure 4)}

We cut to the frontal medium shot of Juliet walking towards the altar - and us as the camera tracks back with her as if leading her towards Romeo and her destiny (Figure 4). It is Juliet's camera - as it represents Juliet's decision; at the same time, the tracking connotes Romeo's attraction that she cannot resist. Her plain white dress sculpts her adolescent figure emphasizing her young age, but the adult bridal hair-style, however rushed, is a testimony of her maturity. There is no veil needed - her innocence is apparent - however the lack of the veil reminds us of the secret character of this wedding, and of Juliet's conscious sacrifice of the wedding luxuries that would be natural to her social status and wealth, which she accepts in the name of love. The heavenly lyrics maintain the message of brotherhood with an emphatic "Oh, yeah!", and Juliet's emotional action [TO ANTICIPATE] connotes hope, which combination brings in the subtext of inner peace (CS 1) and acceptance (CS 2). In the background we see Nurse in her red suit, connoting alert and suffering, who leans towards Juliet: Juliet attracts suffering - true love always does. The subtext that results from the clash of the foreground and background mise-en-scène, and lies in the cognitive space in-between, is the anticipation of Juliet's sacrifice (CS 3).

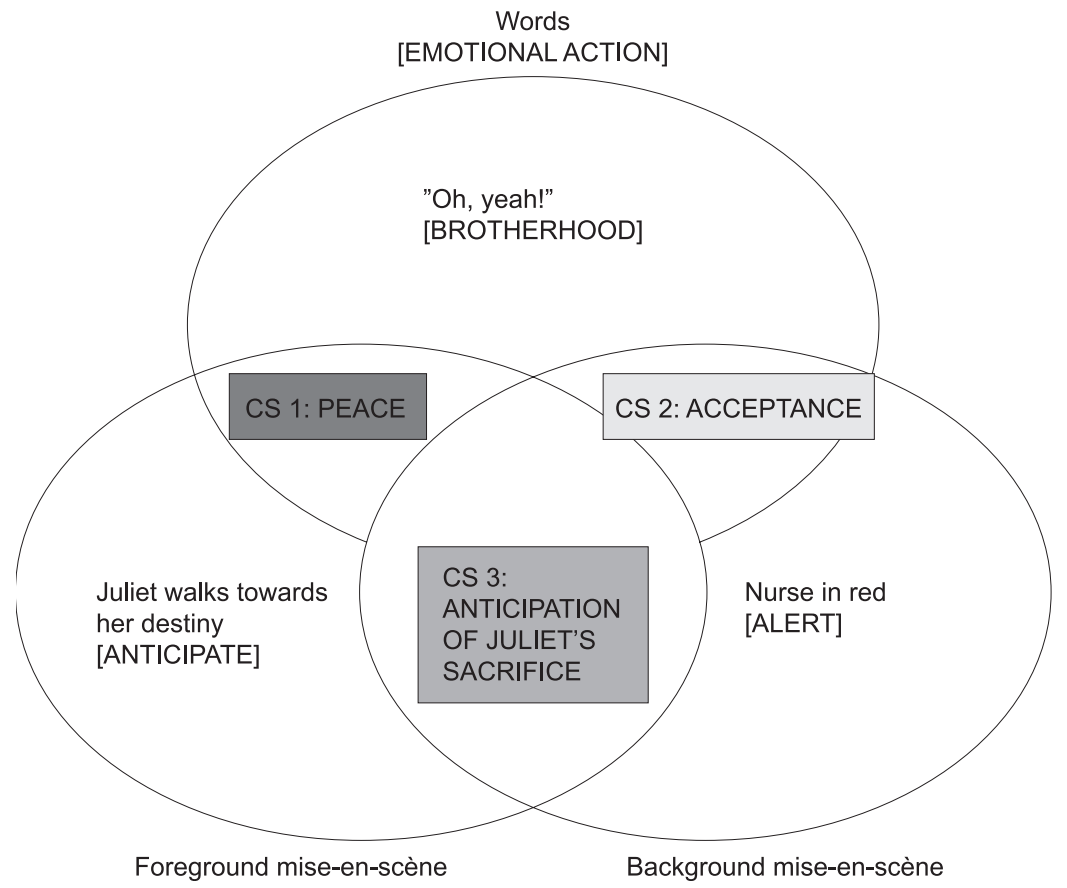

Figure 4: The breakdown of the subtextual interdependences in shot B [TC 54:00] 
The overall subtextual message of the shot, its metasubtext that results from the combination of cognitive spaces $1-3$, becomes Juliet's peaceful anticipation of her future sacrifice in love.

\section{SHOT C (Figure 5)}

In the very foreground, Romeo awaits her at the altar. His blue suit, perhaps a little boyish, is a vivid reminder of his former baptismal initiation in the sacredness of love that takes place in the balcony scene (Litwin 2017), and as he immerses in his emotional action [TO CONTEMPLATE JULIET], the suit's boyishness stands in drastic contrast with Romeo's unexpected maturity. For he has undergone a major transformation: the self-centered, oversexualized boyish poet of many words has yielded to a responsible, caring gentleman of virtue. The virtue of manliness emanates from his eyes and his whole self. Romeo has become a man - a rock to rely on.

His transformation is so spectacular that Balthazar, his best man standing by his side, looks at him in astonishment - and becomes a quiet confirmation of his new self. The camera emphasizes the depth of Romeo's newly-gained manliness by an insightful tracking-in, and if the camera movement represents the approaching Juliet - so the greater Romeo's spirit of readiness to receive her. The divine lyrics boost the spirituality of the moment: "Some day a spirit will take you and guide you there", and the frontier of the foreground mise-en-scène and the words becomes the subtext of spiritual responsibility (CS 1). The altar in the background and the red prayer stand connote sacrifice, but the priest's presence appeases the harshness, and the tabernacle among the heavenly-blue statues in the further background brings in the subtext of the soothing warmth of God-with-us (CS 2). After all, the tabernacle, being the central part of the altar, is the center of the universe (Limon 2001). Romeo smiles, rejoicing in love, and his manliness — and the clash between the foreground and the background mise-en-scène creates the subtext of Romeo's joyful sacrifice in love (CS 3).

And it is Romeo's manliness that constitutes the overall space-negotiated metasubtext of the shot: his gaining maturity as a man through his acceptance of love as a joyful spiritual responsibility and sacrifice - in the name, and with the guidance, of God-with-us.

Romeo's smile transitions us to the next shot. 


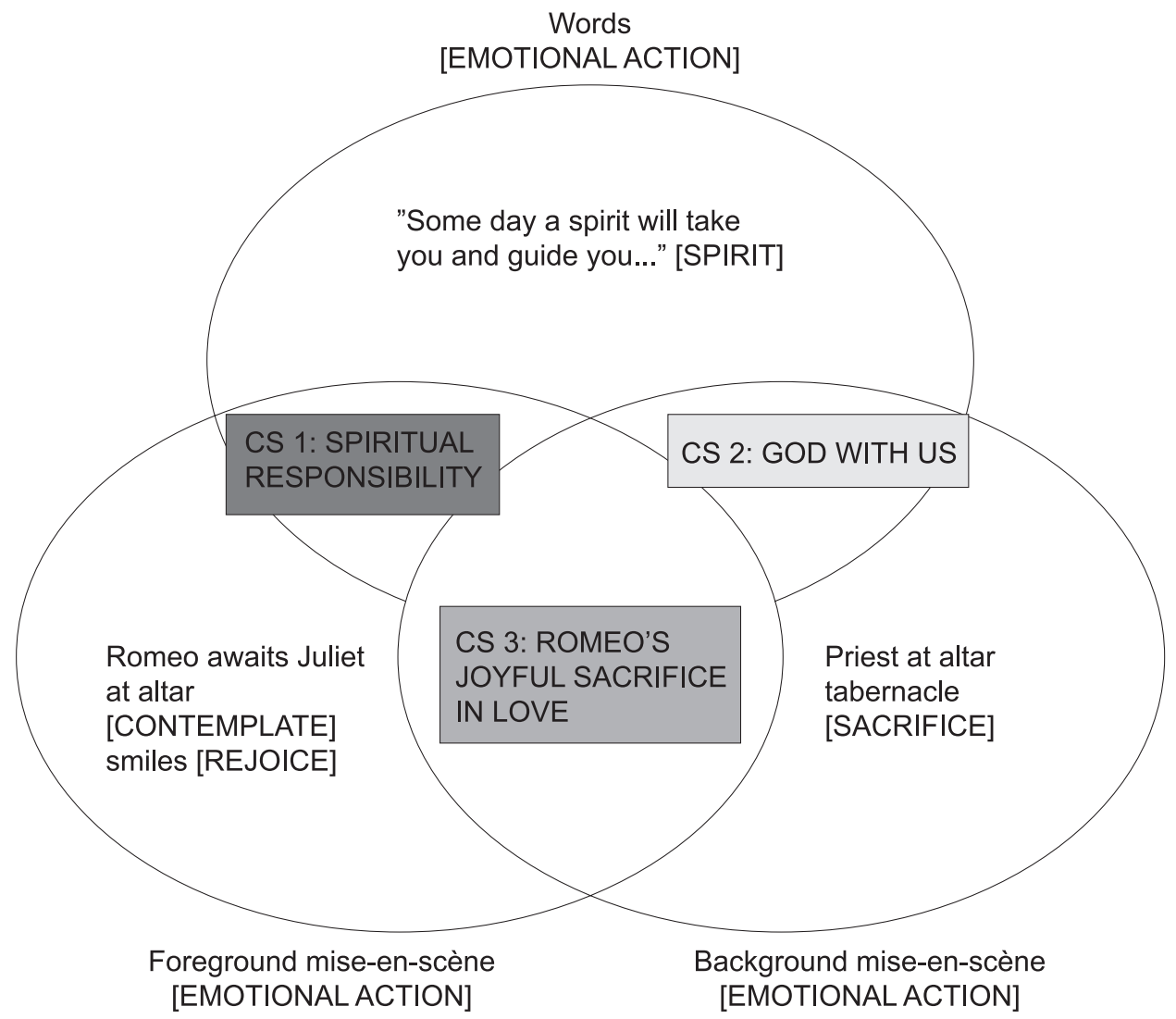

Figure 5: The breakdown of the subtextual interdependences in shot C [TC 54:06]

\section{SHOT D (Figure 6)}

Juliet smiles back, embracing her fate, as she continues walking, and for a moment loses the air of suffering in a gorgeous, youthful smile. In this shot the motionless camera allows her to approach - representing Romeo's motionless contemplation of her, or perhaps Juliet's own coming of age, as she literally grows on the screen: from a medium shot through a medium-close-up and ending on a beautiful, mature close-up in which she looks up and faces her sacrifice. Her eye-line seeks Romeo off-screen while she pursues her emotional action: ask for guidance. The Godly lyrics reassure Juliet by an emphatic culmination of the line "guide you there", subtextually bringing her a promise of guidance (CS 1).

In continuity to shot $\mathrm{B}$, the redness of Nurses suit in the background keeps reminding us that this marriage balances on the verge of a sacrifice, and suffering will be a part of it. However, unlike in shot B, the background is blurry and dominated by the optimistic foreground volume-wise - which, when juxtaposed with 
the heavenly reassurance, brings hope (CS 2). Since mise-en-scène-wise Juliet's optimism in the foreground outbalances the prospects of suffering suggested by the background, the message of the subtextual intersection becomes: love is greater that sacrifice (CS 3).

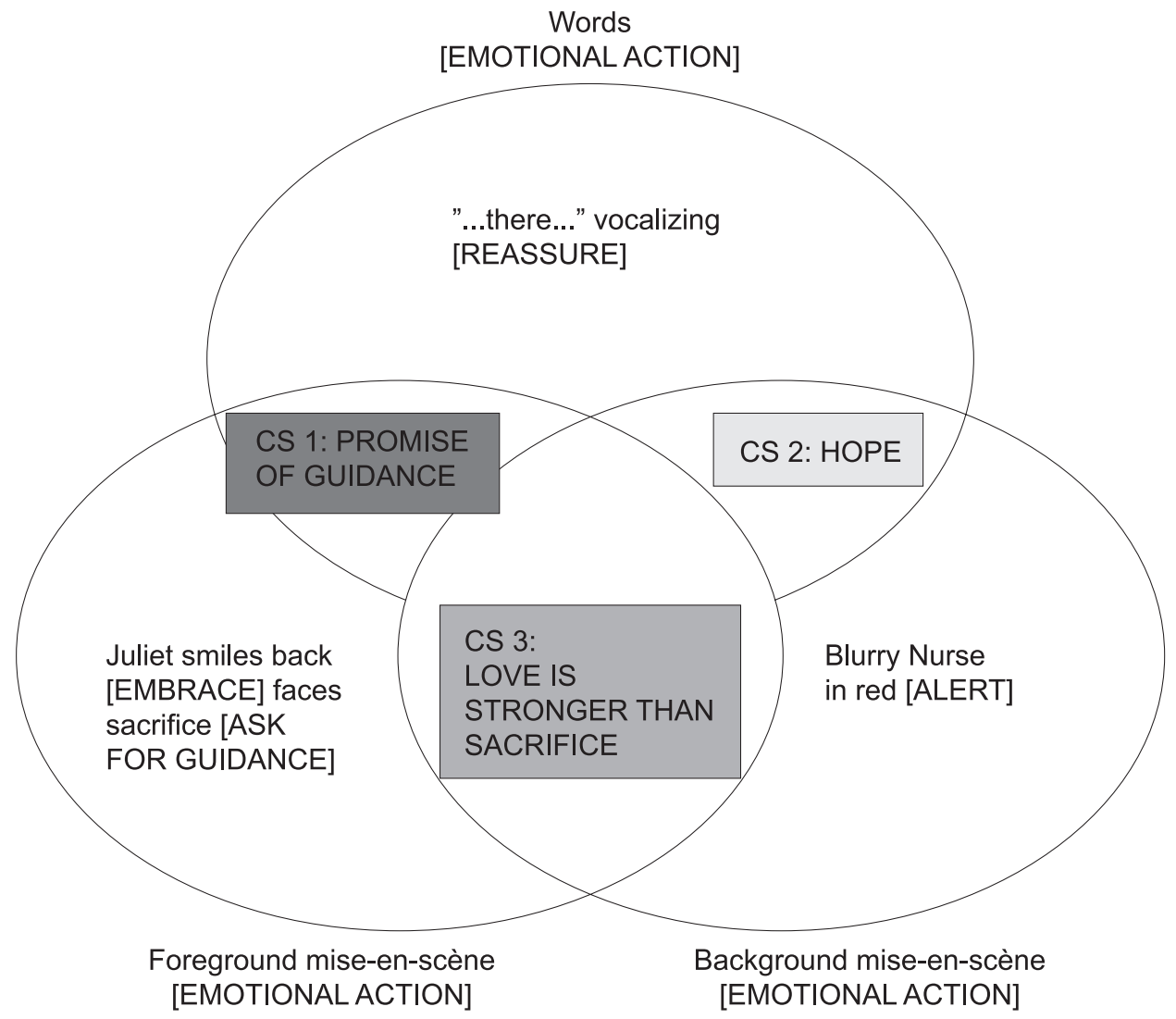

Figure 6: The breakdown of the subtextual interdependences in shot D [TC 54:10]

The median space-negotiated metasubtext of cognitive spaces 1-3 in shot $D$ is therefore: love can overcome the sacrifice - with God's guidance.

\section{SHOT E (Figure 7)}

We cut back to Romeo at the altar. As the camera continues tracking-in on Romeo from a medium close-up to a close-up, we see his mature eyes that express his emotional action: he BESTOWS himself upon Juliet. The lyrics continue the Divine message, or perhaps Romeo's thoughts full of sympathy and strong feelings: "I know you've been hurting, but I've been waiting to...", which reassures us that Romeo is ready to take care of Juliet (CS 1). The lyrics in the juxtaposition with 
the background mise-en-scène of the altar being gradually excluded from the open frame, and the image of Romeo taking over the physical space, create the subtext of Romeo removing Juliet's suffering (CS 2). Visually, the two layers of the frame combine in the subtextual statement: Romeo will take Juliet's suffering on his shoulders (CS 3).

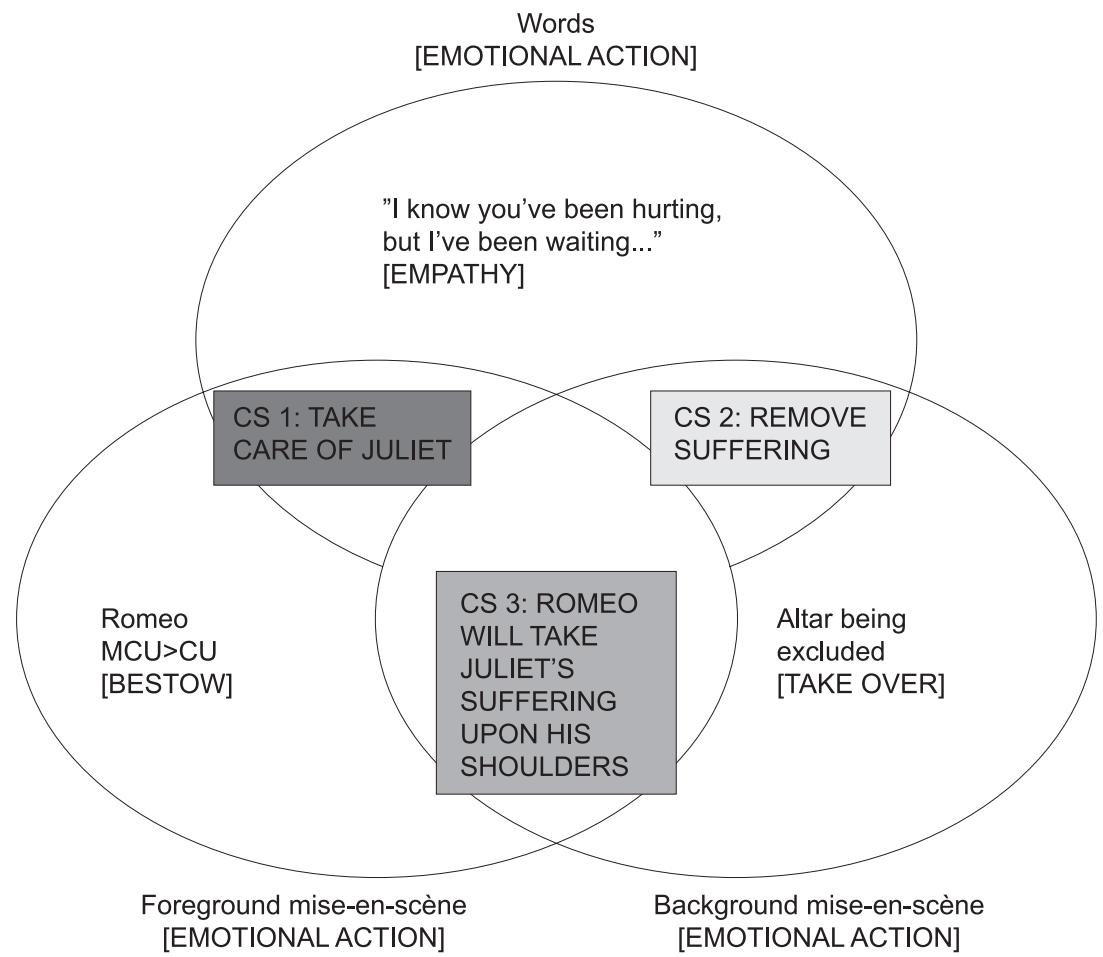

Figure 7: The breakdown of the subtextual interdependences in shot E [TC 54:14]

The subtextual cognitive spaces 1-3 of shot E unite in the metasubtext of Romeo laying foundation for the full realization of his manliness.

\section{SHOT F (Figure 8)}

Romeo enters Juliet's frame and joins her lovingly. Seeing her restlessness he looks at her knowingly, calming her down and reassuring of his support as the lyrics embrace her and hug tenderly: "...to be there for you. And I'll be there just helping you out whenever I can" - confirming their union (CS 1). The warmth of the lyrics stands in contrast to the harsh redness of Nurse's suit that is looming in the background between Romeo and Juliet, which connotes a threat that sacrifice and suffering could separate them. The clash creates the subtext that love 
overcomes obstacles (CS 2). Therefore, as Romeo and Juliet take a deep breath and set off together, we know that subtextually they take love (and sacrifice) on their shoulders as a married couple (CS 3), and — as the metasubtext - that they do it with optimism, trusting their capability to overcome the obstacles together.

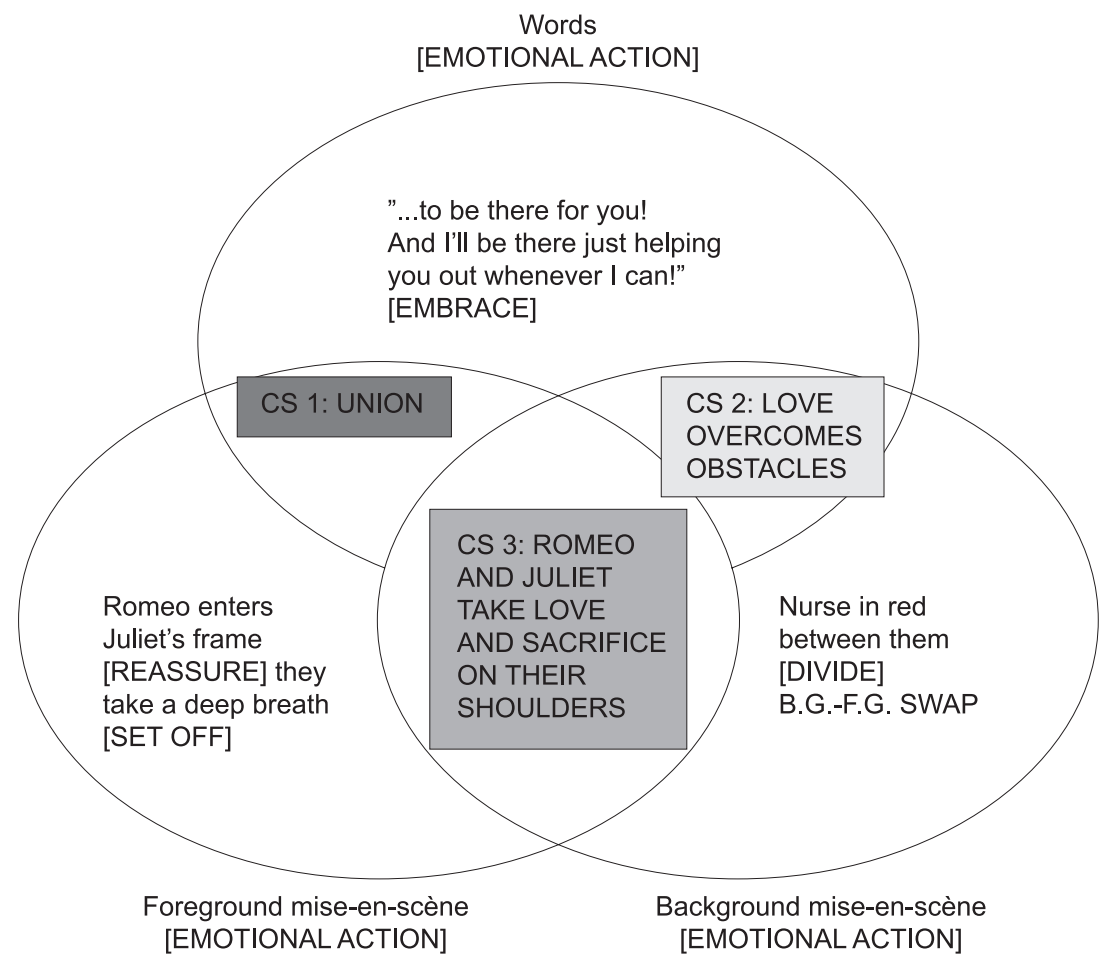

Figure 8: The breakdown of the subtextual interdependences in shot F [TC 54:21]

\section{SHOT G (Figure 9)}

The cutaway to the choir soloist brings back the connotation of the heroes' innocence as he prays for them with the emotional action of begging in his eyes, and sings out "Everybody's free!" emphatically — reminding them of their free will and empowering them on behalf of God, and therefore allowing the subtext of Might as a result of the combination of innocence and free will (CS 1). The free will also overcomes suffering (CS 2) and enables a truthful marriage (CS 3). The mise-en-scène clash between the innocence of the choir soloist in the foreground and the connotation of suffering inspired by the redness of Nurse's suit in the background results in the subtextual statement that innocence is more powerful than suffering (CS 4). The perspective of suffering is unable to prevent the truthful marriage - in the further background Romeo and Juliet stand at the altar taking their oath and the subtext here is: against all odds (CS 5). The subtextual statement 
of the divine destiny created by the juxtaposition of the marriage and the altar art in the furthermost background (CS 6) - and of God's Might connoted by the intersection of the altar art and the emphatic "Everybody's free!" lyrics (CS 7) inspire the metasubtext of the shot: God-empowered innocence overcomes suffering and enables a truthful marriage against all odds.

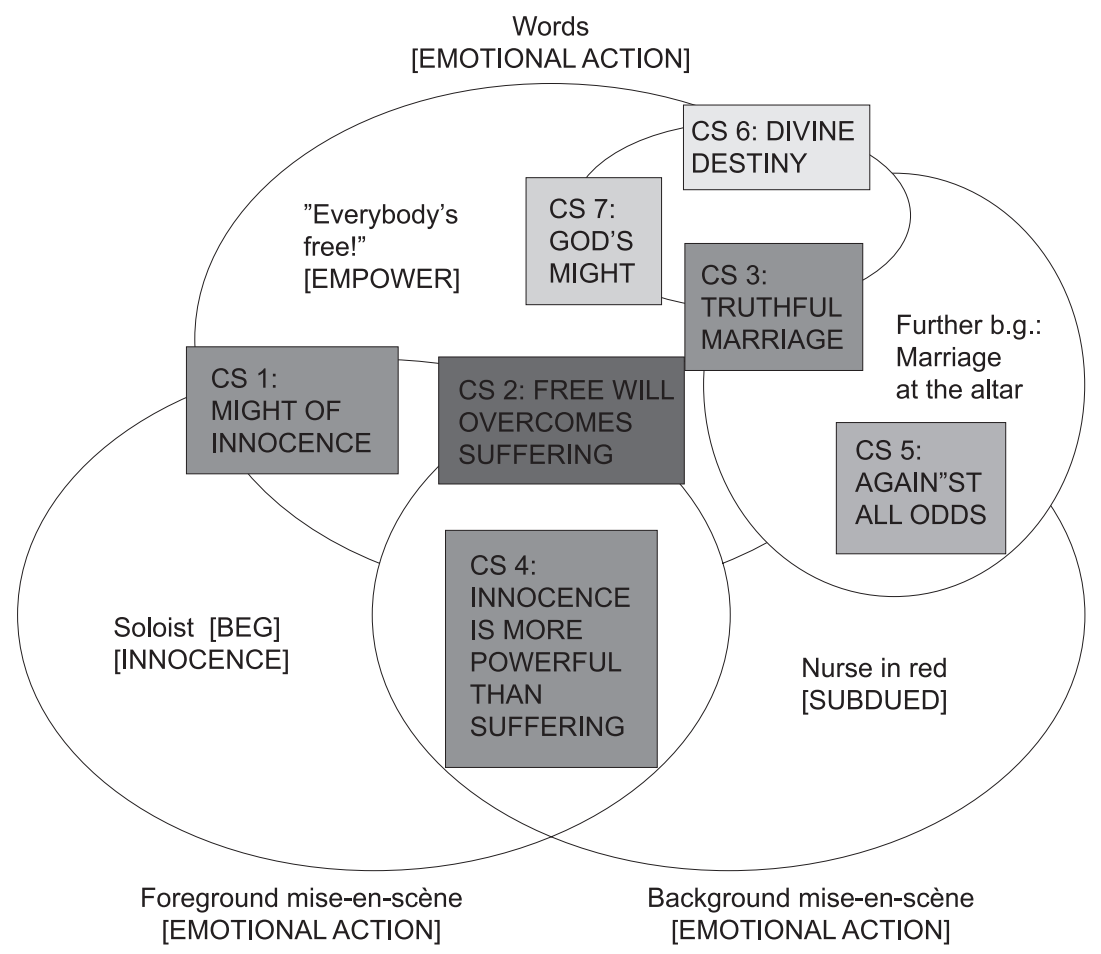

Figure 9: The breakdown of the subtextual interdependences in shot G [TC 54:37].

\section{SHOT H (Figure 10)}

The subsequent cutaway focuses on Nurse as she runs forward hastily to be with the newlyweds and support them in their mothers' stead — with pride in her eyes. She receives a powerful divine confirmation from the choir soloist in the form of an emphatic "Yeah, yeah, yeah!". The redness of her suit - connoting the sacrificial suffering - is overwhelming as it claims the entire foreground. However, it is elevated this time - it gains a human face (CS 1). The driver/ bodyguard follows Nurse and his emotional action [TO GUARD] is in turn elevated by the choir soloist's divine confirmation. The cognitive space in-between gains the quality of a guardian angel's presence (CS 2). Nurse's proud support, boosted by the divine confirmation and the angelic air, culminates in a powerful cognitive statement of the subtext that sacrifice is the highest form of love - the 
divine love (CS 3). By the combination of cognitive spaces 1-3 we receive the metasubtext: sacrifice is tamed, and its burden is reversed.

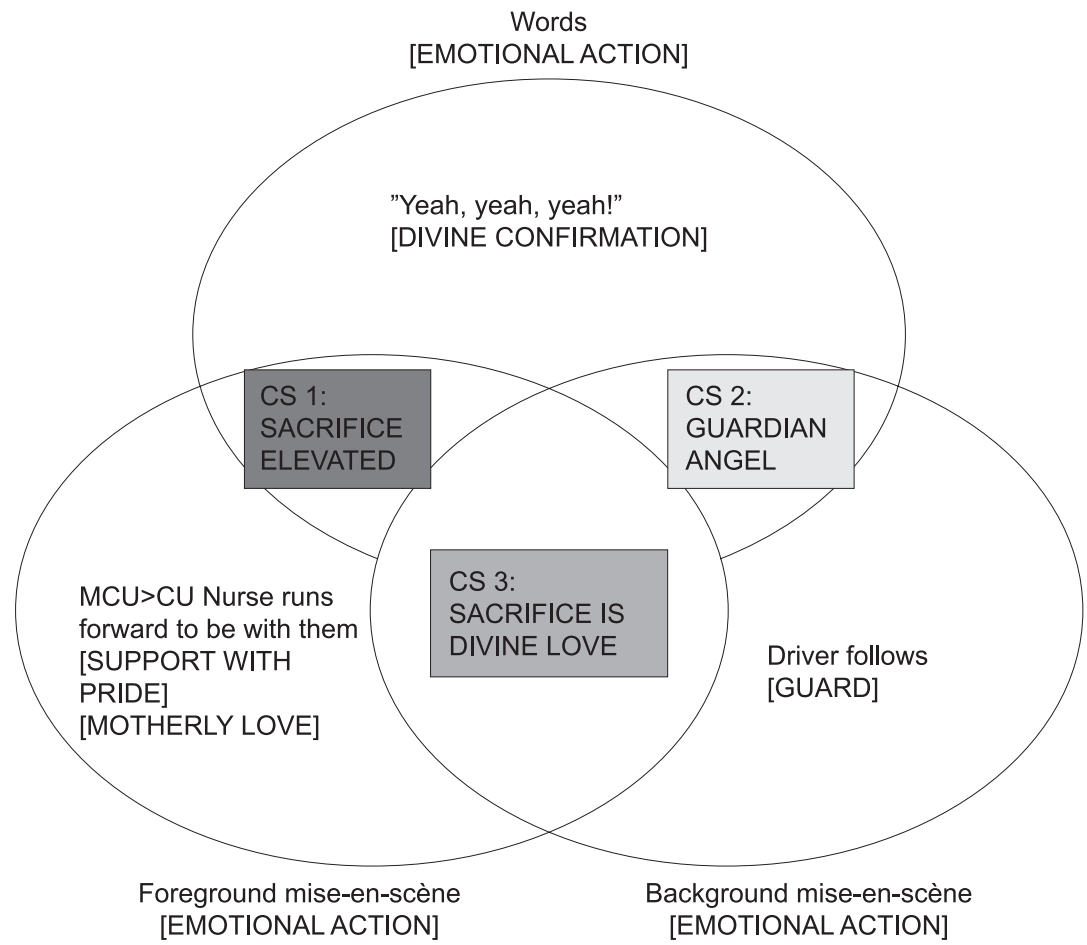

Figure 10: The breakdown of the subtextual interdependences in shot H [TC 54:40]

\section{SHOT J (Figure 11)}

In the foreground of shot $\mathrm{J}$ the frame shows Romeo and Juliet from behind. Like a firm rock stated by their emotional action [TO STAND GROUND], they form a frame-within-the-frame for Father Lawrence who speaks the words of wisdom:

These violent delights have violent ends and in their triumph die like fire and powder which as they kiss consume. The sweetest honey is loathsome in its own deliciousness.

The words communicate a clear warning against their family conflict ("violent delights have violent ends", "die", "fire and powder"), but perhaps more poignantly against idealism in love ("the sweetest honey is loathsome") revealing the true nature of human emotions - a game of extremes based on constant change which mustn't be mistaken for love. A slight simultaneous tracking-in/boom-up of the camera emphasizes the firmness of Romeo and Juliet's standpoint, and the red hue of the lighting on their faces keeps the memory of suffering in love alive, and ensures the heroes', as well as the audience's, constant awareness of it. The 
juxtaposition of the foreground mise-en-scène with Father Lawrence's words of wisdom creates the cognitive space communicating the subtext of love's capacity to withstand trial (CS 1).

On the other hand, the background of the shot shows Father Lawrence's concerned face as he speaks. While his words communicate a warning his eyes express the emotional action [TO BEG]: he is begging them to live up to their ideals, and his priestly, God-given authority, represented by his stole ornamented with the graphic red pattern of the cross, ensures them of God's support. Mise-enscène-wise, he is standing under the cross which can be seen behind him above his head. Yes, love is sacrifice, but God will be there with them. The cognitive frontier of the background mise-en-scène and the verbal layers becomes the subtextual space: it is all up to them and they can do it with God's support (CS 2). Since their heads form a rock-like frame-within-the-frame for Father Lawrence's face - and his emotional begging accentuates their power and emphasizes their determination - the subtextual connotation of the cognitive space in-between can be stated as follows: they carry the world upon their shoulders (CS 3).

Therefore, the metasubtext uniting cognitive spaces $1-3$ becomes a statement of freedom in love: human love built on the rock of the divine love is freedom.

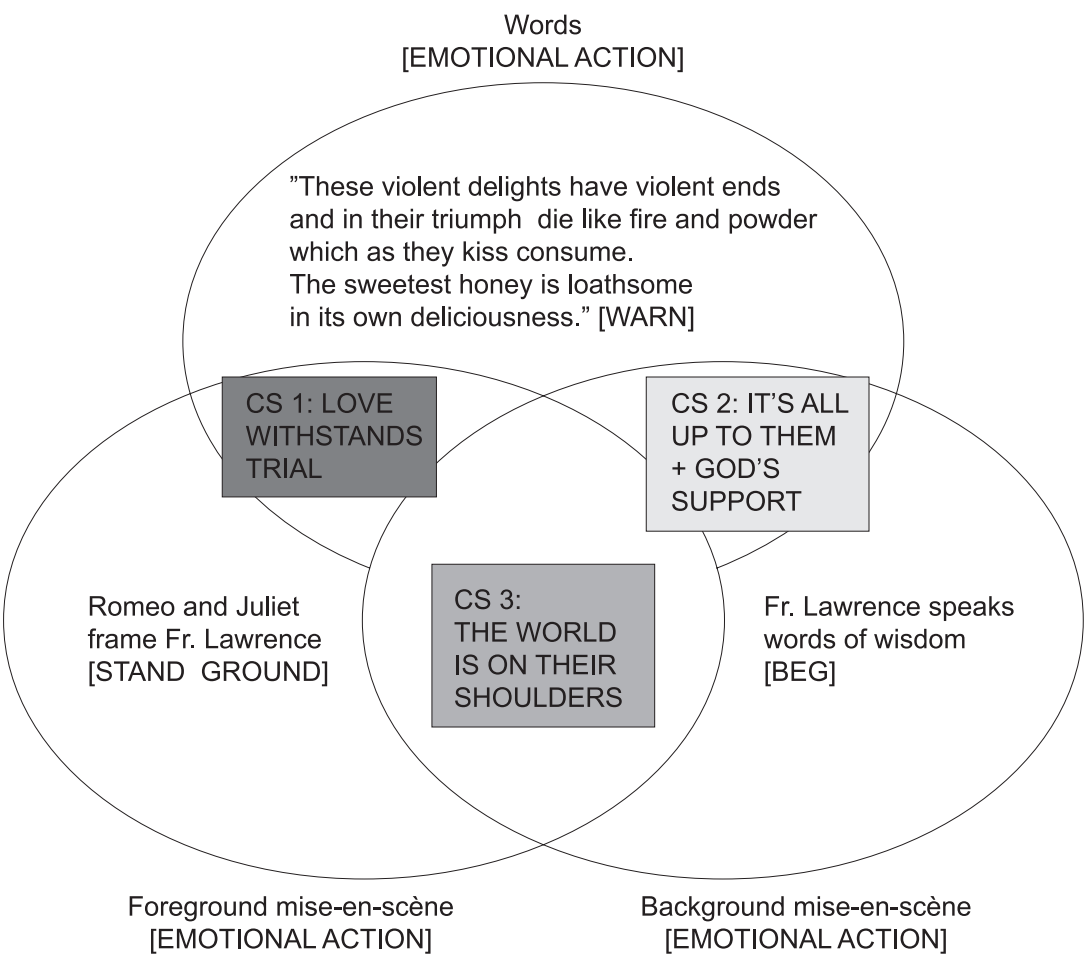

Figure 11: The breakdown of the subtextual interdependences in shot J [TC 54:44] 


\section{SHOT K (Figure 12)}

In the cutaway immediately following the statement of love as freedom, Romeo puts the wedding band on Juliet's finger: it is a rosary with the cross exposed in the central spot. The connotation of Christ marrying His Church returns and the interdependence of the bride and groom is emphasized by the contrast between the firmness of Romeo's gesture and the delicateness of Juliet's trembling hand. Father Lawrence's emphatic words, "therefore love moderately", remind us of God's support connoted previously in shot $\mathrm{J}$ - and the space in-between becomes the subtext of the Divine Wisdom in Love (CS 1). Juliet's bouquet of white lilies in the background connotes Christ's burial (Kopaliński 85) and therefore brings back the notion of suffering, but when juxtaposed with God's support expressed verbally - the message of the frontier reminds us that Christ's death was a part of God's plan for our salvation (CS 2). The juxtaposition of Christ marrying His Church in the foreground with Christ's burial in the background creates a new subtextual meaning in-between: the anticipation of resurrection (CS 3).

The metasubtext of shot $\mathrm{K}$ built upon cognitive spaces $1-3$ is God's love which gives them a blessing.

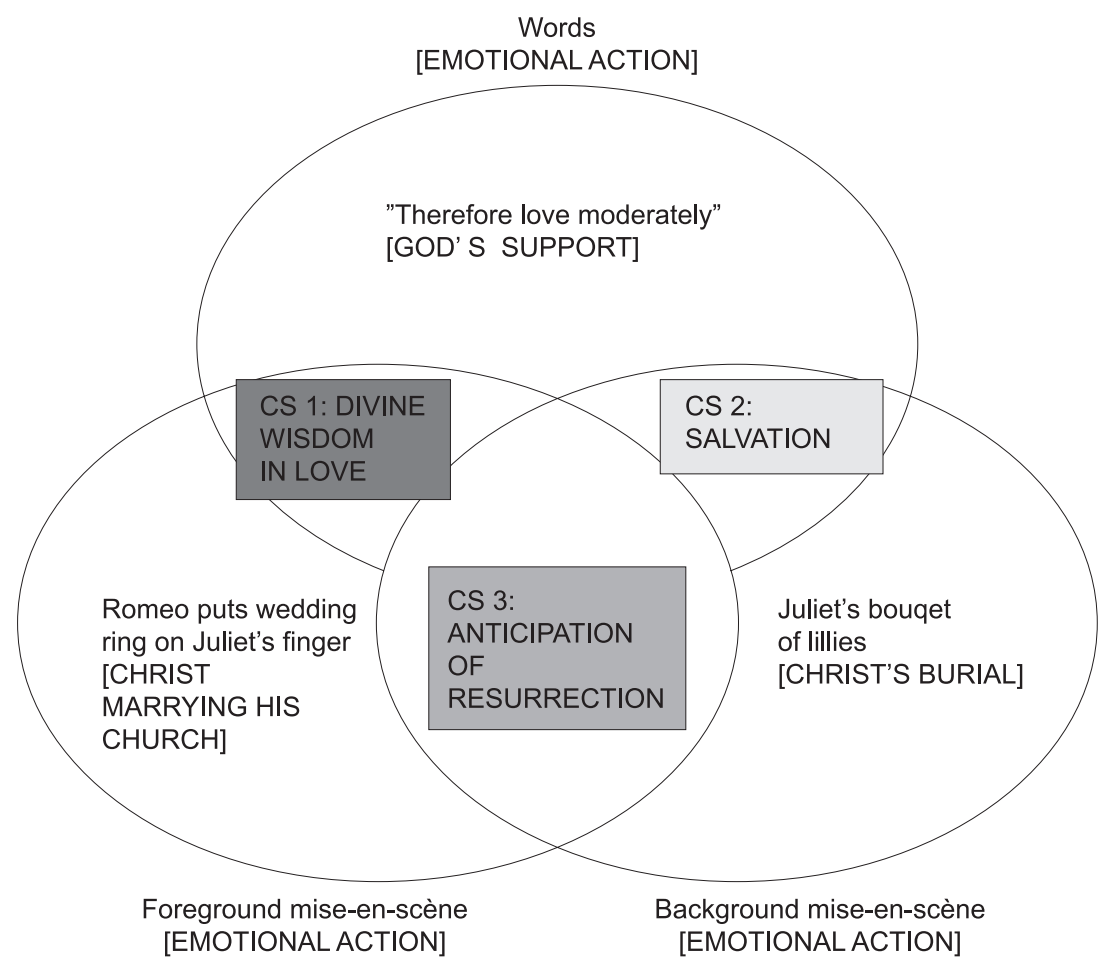

Figure 12: The breakdown of the subtextual interdependences in shot K [TC 55:00] 


\section{SHOT L (Figure 13)}

The blessing is confirmed as we cut back to the continuation of shot $\mathrm{J}$ in its new configuration, in which Father Lawrence, in the background, sends Romeo and Juliet out onto their journey as husband and wife by orchestrating their first kiss. In the foreground, the heroes welcome the invitation eagerly and seal their oath with a kiss - joyfully, bravely, and with youthful determination. Father Lawrence's words: "Romeo shall thank thee, daughter, for us both" are meant to enhance the heroes' sense of responsibility, and the intersection of the words and the foreground miseen-scène creates the subtext of Romeo and Juliet claiming their happiness (CS 1). As Father Lawrence orchestrates their first kiss with a gesture, his eyes express the emotional action [TO CHALLENGE], which in juxtaposition with the words connotes the subtext of taking responsibility and accepting the commitment (CS 2).

While Father Lawrence challenges Romeo and Juliet, they answer with determination, courage and joy, and withstand the challenge. The seal of their kiss unites them - also in the physical space of the frame - as they spatially dominate Father Lawrence, literally removing him from view by claiming the entire foreground of the frame. The resulting frontier in-between is a subtextual statement of Romeo's sense of mission as a husband validated by Juliet's kiss (CS 3). They need each other for their happiness, the fulfillment of their commitment, and the success of their mission in marriage. The metasubtext of the shot is their togetherness - they validate each other.

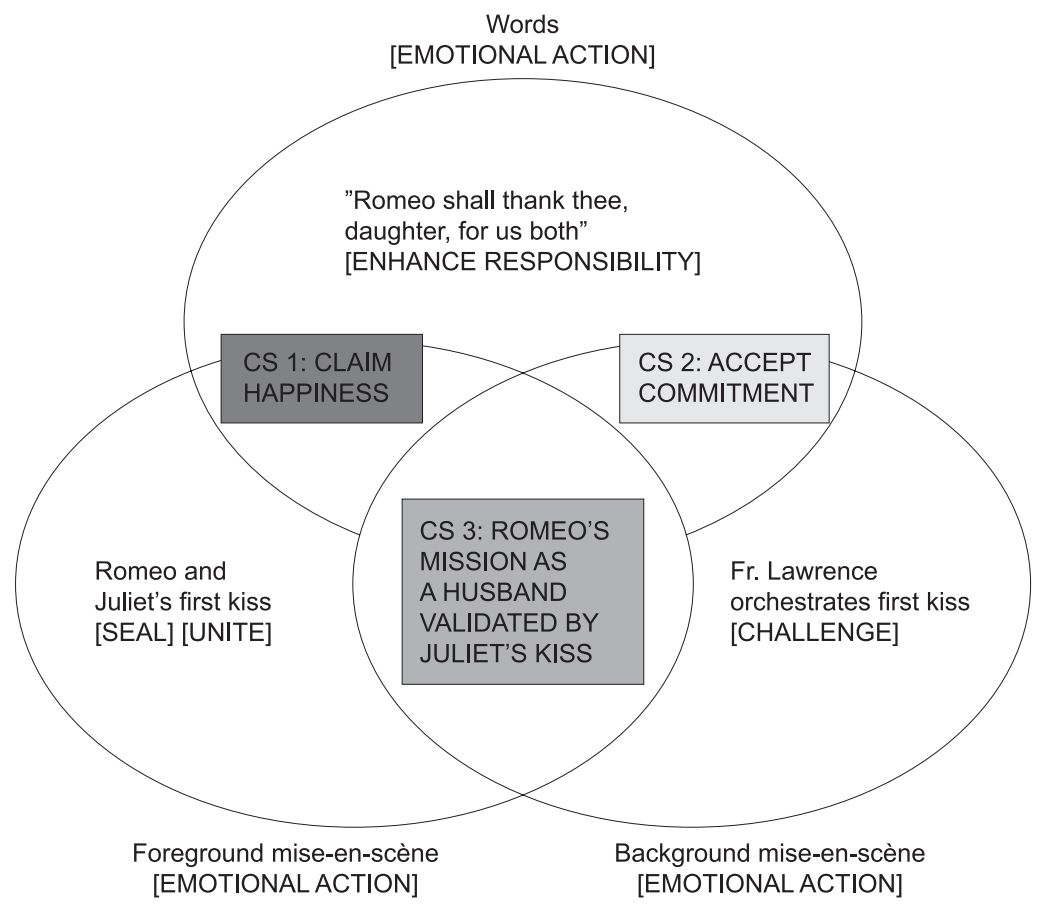

Figure 13: The breakdown of the subtextual interdependences in shot L [TC 55:03] 
According to the same principle of multidirectional interdependences we can establish the overall subtext of the entire scene - the megasubtext - as the frontier-negotiated median of all the cognitive spaces in-between the shots within the scene. For the wedding scene in William Shakespeare's Romeo + Juliet it could be as follows: a husband and wife find the truth as they assume their mission of love in marriage, based on the ideal of the divine, cross-inspired love.

\section{Conclusions}

Subtext is a space-negotiated cognitive unit, and we gain access to it step by step, in layers, which are revealed as a cascade of foreground-background configurations within the directorial triad of word - emotional action - mise-en-scène. Like a frontier that needs to be constantly reclaimed and redefined, the subtext evolves with each shot according to a set of principles. The metasubtext of the shot is the result of the multidirectional spatial negotiation between different visual and verbal layers of the shot on the foreground-background axis in synchronicity with the emotional action. The megasubtext of the scene is the result of the multidirectional spatial negotiation among and within the subtextual spaces in-between the shots; it is the median of all the metasubtexts. By analogy, the subtext of the entire story the total subtext - is revealed as the cognitive spaces in-between and within the sequences of multidirectional megasubtexts.

Ultimately, the role of the subtext is to reveal the emotional truth. Indeed, subtext is such stuff as truth is made on. In screen reality - and beyond.

\section{References}

\section{Primary sources}

Luhrmann, B. 1996. William Shakespeare's Romeo + Juliet. USA n.p.: 20th Century Fox.

\section{Secondary sources}

Adler, S. 1988. The Technique of Acting. New York: Bantam Books.

Bogart, A. 2001. A Director Prepares. London-New York: Routledge.

Cathechism of the Catholic Church. 1995. New York: Random House.

DeKoven, L. 2006. Changing Direction. Burlington: Focal Press.

Eco, U. 1979. A Theory of Semiotics. Bloomington: Indiana University Press.

Elam, K. 1994. The Semiotics of Theatre and Drama. New York: Routledge.

Holy Bible, 2007. San Francisco: Harper Collins Publishers.

Kopaliński, W. 2012. Stownik symboli (The Dictionary of Symbols). Warsaw: Oficyna Wydawnicza RYTM. 
Limon, J. 2001. Między niebem a scena (Between Heaven and Stage). Gdańsk: słowo/obraz terytoria.

Litwin, E. 2017. "Trust, Infinity and the Philosophy of the Divine Mercy. Breaking the Star Crossed Paradigm in William Shakespeare's Romeo + Juliet by Baz Luhrmann.” Gdańsk: the 2017 Congress of the European Shakespeare Research Association.

Meisner, S. and D. Longwell. 1987. Sanford Meisner on Acting. New York: Random House.

Nuttall, A.D. 2007. Shakespeare the Thinker. New Haven-London: Yale University Press.

Stanislavski, C. 2003. An Actor Prepares. Reynolds Hapgood E. (trans.). New York: Routledge. Strasberg, L. 1987. A Dream of Passion: The Development of The Method. New York: Plume.

Weston, J. 1996. Directing Actors. Studio City: Michael Wiese Productions.

Wittgenstein, L. 1999. Tractatus Logico-Philosophicus. Mineola-New York: Dover Publications, Inc. 